\title{
CONTOH SITASI DAN DAFTAR PUSTAKA
}

\author{
MUHAMAD ANDIKA SASMITA SAPUTRA \\ Email: muhamad.andikasp@gmail.com
}

\begin{abstract}
Abstrak
Penuliasan sitasi dan referensi merupakan item yang sangat identik dan penting dalam sebuah karya baik itu buku, artikel, proposal, makalah, skripsi, tesis, disertasi dan lain sebagainya. Hal ini dilakukan sebagai bentuk tanggung jawab dari Si pembuat karya dalam mengutip hasil karya, ungkapan, atau pernyataan seseorang. Contoh tataletak sitasi dan refernsi yang dibuat dalam artikel ini berbentuk paragraf yang dinarasikan hal ini bermanfaat agar para pembaca dapat langsung membedakan dimana letak posisi sitasi dan bagaimana saat ditulis dalam daftar pustaka, pembaca harus melihat secara teliti karena setiap style memiliki sitasi yang hampir mirip namun terdapat perbedaan termasuk tanda baca. Artikel ini hanya memuat konten tentang contoh sitasi dan referensi dan tidak membahas tentang hal-hal yang berhubungan dengan definisi, sejarah, dan lain-lain lebih detail.
\end{abstract}

Kata Kunci : Sitasi, Daftar Pustaka, Referensi

\begin{abstract}
Abstrack
Writing citations and references are very identical and important items in a work, be it books, articles, proposals, papers, theses, theses, dissertations and so on. This is done as a form of responsibility from the creator of the work in citing someone's work, expressions, or statement. Examples of the layout of citations and references in this article are made in the form of narrated paragraphs, this is useful so that readers can immediately distinguish where the citations are located and how when they are written in the bibliography, readers must look carefully because each style has almost similar citations but there are differences including punctuation. This article only contains content about examples of citations and references and does not discuss matters related to definitions, history, and others in more detail.
\end{abstract}

Keyword : Citations, Bibliography, References

\section{AMERICAN POLITICAL SCIENCE ASSOCIATION (APSA) STYLE CONTOH SITASI}

Ini adalah contoh kalimat yang dilengkapi dengan sitasi, beberapa pendapat yang diparaprase menjadi satu kalimat sehingga sitasinya digabung (Bakri 2017; Hidayat 2009; House, Goetz, dan Dowell 2015). Ini adalah contoh kalimat yang dilengkapi dengan sitasi, beberapa pendapat yang diparaprase menjadi satu kalimat sehingga sitasinya digabung (Kemdikbud 2016; Lestari dan Rosyidah 2011; Martini 2007; Potter dan Perry 2010). Ini adalah contoh kalimat yang dilengkapi dengan sitasi (Janka et al. 2017). Menurut Utami (2017) ini adalah contoh kalimat yang dilengkapi dengan sitasi, Insuranceinstitute (2017) dan Saputra (2017) ini adalah contoh kalimat yang dilengkapi dengan sitasi.

\section{CONTOH DAFTAR PUSTAKA}

Bakri, Maria H. 2017. Manajemen Keperawatan, Konsep dan Aplikasi dalam Praktik Keperawatan Profesional. Yogyakarta: Pustaka Baru Press.

Hidayat, Dede Rahmat. 2009. Ilmu Perilaku Manusia, Pengantar Psikologi untuk Tenaga Kesehatan Medis. Jakarta: Trans Info Media.

House, Sheryl K., Mary Ann Goetz, dan Susan Dowell. 2015. "Utilization of Nursing Home Residents for Development of Assessment Skills." Teaching and Learning in Nursing 10(3): 128-31. http://dx.doi.org/10.1016/j.teln.2015.01.005.

Insuranceinstitute. $2017 . \quad$ "Mentoring Models." Insuranceinstitute. https://www.insuranceinstitute.ca/fr/Mentoring/for-organizations/mentoring-models (Desember 22, 2017).

Janka, A. et al. 2017. "Biofeedback Training in Crisis Managers: A Randomized Controlled Trial." Applied Psychophysiology Biofeedback 42(2): 117-25. 
Kemdikbud. 2016. 4 Pedoman Umum Ejaan Bahasa Indonesi Pedoman Umum Ejaan Bahasa Indonesi. 4 ed. Jakarta: Kementrian Pendidikan dan Kebudayaan http://badanbahasa.kemdikbud.go.id/lamanbahasa/sites/default/files/PUEBI.pdf\#page=8\&zoom=auto,195,422 .

Lestari, Citra Ega, dan Rosyidah. 2011. “Aanalisis Kepatuhan Perawat Pada Standar Asuhan Keperawatan Di Unit Rawat Inap Kelas III RSU PKU Muhammadiyah Bantul Yogyakarta Tahun 2010.” Jurnal Kesehatan Masyarakat (Journal of Public Health) Universitas Ahmad Dahlan 5(1): 45-49.

Martini. 2007. "Hubungan Karakteristik Perawat, Sikap, Beban Kerja, Ketersediaan Fasilitas dengan Pendokumentasian Asuhan Keperawatan di Rawat Inap BPRSUD Kota Salatiga.” Universitas Diponegoro Semarang.

Potter, dan Perry. 2010. Fundamental Keperawatan. 7 ed. Jakarta: Salemba Medika.

Saputra, Muhamad Andika Sasmita. 2017. Dengarkanlah. Yogyakarta: Deepublish. https://penerbitbukudeepublish.com/shop/buku-dengarkanlah/.

Utami, Ian. $2017 . \quad$ "Ketidak Patuhan." $18 \quad$ Januari $2017:$ 1-4. https://www.scribd.com/document/336893143/ketidakpatuhan (Juni 26, 2017).

\section{AMERICAN PSYCHOLOGICAL ASSOCIATION (APA) STYLE}

\section{CONTOH SITASI}

Ini adalah contoh kalimat yang dilengkapi dengan sitasi, beberapa pendapat yang diparaprase menjadi satu kalimat sehingga sitasinya digabung (Bakri, 2017; Hidayat, 2009; House et al., 2015). Ini adalah contoh kalimat yang dilengkapi dengan sitasi, beberapa pendapat yang diparaprase menjadi satu kalimat sehingga sitasinya digabung (Kemdikbud, 2016; Lestari \& Rosyidah, 2011; Martini, 2007; Potter \& Perry, 2010). Ini adalah contoh kalimat yang dilengkapi dengan sitasi (Janka et al., 2017). Menurut Utami (2017) ini adalah contoh kalimat yang dilengkapi dengan sitasi, Insuranceinstitute (2017) dan Saputra (2017) ini adalah contoh kalimat yang dilengkapi dengan sitasi.

\section{CONTOH DAFTAR PUSTAKA}

Bakri, M. H. (2017). Manajemen Keperawatan, Konsep dan Aplikasi dalam Praktik Keperawatan Profesional. Pustaka Baru Press.

Hidayat, D. R. (2009). Ilmu Perilaku Manusia, Pengantar Psikologi untuk Tenaga Kesehatan Medis. Trans Info Media.

House, S. K., Goetz, M. A., \& Dowell, S. (2015). Utilization of Nursing Home Residents for Development of Assessment Skills. Teaching and Learning in Nursing, 10(3), 128-131. https://doi.org/10.1016/j.teln.2015.01.005

Insuranceinstitute. (2017). Mentoring $\quad$ Models. https://www.insuranceinstitute.ca/fr/Mentoring/for-organizations/mentoring-models

Janka, A., Adler, C., Brunner, B., Oppenrieder, S., \& Duschek, S. (2017). Biofeedback Training in Crisis Managers: A Randomized Controlled Trial. Applied Psychophysiology Biofeedback, 42(2), 117-125. https://doi.org/10.1007/s10484-017-9360-6

Kemdikbud. (2016). Pedoman Umum Ejaan Bahasa Indonesi. In Pedoman Umum Ejaan Bahasa Indonesi (4 ed., Vol. 4). Kementrian Pendidikan dan Kebudayaan RI. https://doi.org/10.5851/kosfa.2016.36.6.807

Lestari, C. E., \& Rosyidah. (2011). Aanalisis Kepatuhan Perawat Pada Standar Asuhan Keperawatan Di Unit Rawat Inap Kelas III RSU PKU Muhammadiyah Bantul Yogyakarta Tahun 2010. Jurnal Kesehatan Masyarakat (Journal of Public Health) Universitas Ahmad Dahlan, 5(1), 45-49.

Martini. (2007). Hubungan Karakteristik Perawat, Sikap, Beban Kerja, Ketersediaan Fasilitas dengan Pendokumentasian Asuhan Keperawatan di Rawat Inap BPRSUD Kota Salatiga. Universitas Diponegoro Semarang.

Potter, \& Perry. (2010). Fundamental Keperawatan (7 ed.). Salemba Medika.

Saputra, M. A. S. (2017). Dengarkanlah. Deepublish. https://penerbitbukudeepublish.com/shop/bukudengarkanlah/ 
Utami, I. (2017). Ketidak Patuhan.

18

Januari

2017. https://www.scribd.com/document/336893143/ketidakpatuhan

\section{CHICAGO MANUAL 17th EDITION STYLE}

\section{CONTOH SITASI}

Ini adalah contoh kalimat yang dilengkapi dengan sitasi, beberapa pendapat yang diparaprase menjadi satu kalimat sehingga sitasinya digabung (Bakri 2017; Hidayat 2009; House, Goetz, dan Dowell 2015). Ini adalah contoh kalimat yang dilengkapi dengan sitasi, beberapa pendapat yang diparaprase menjadi satu kalimat sehingga sitasinya digabung (Kemdikbud 2016; Lestari dan Rosyidah 2011; Martini 2007; Potter dan Perry 2010). Ini adalah contoh kalimat yang dilengkapi dengan sitasi (Janka et al. 2017). Menurut Utami (2017) ini adalah contoh kalimat yang dilengkapi dengan sitasi, Insuranceinstitute (2017) dan Saputra (2017) ini adalah contoh kalimat yang dilengkapi dengan sitasi.

\section{CONTOH DAFTAR PUSTAKA}

Bakri, Maria H. 2017. Manajemen Keperawatan, Konsep dan Aplikasi dalam Praktik Keperawatan Profesional. Yogyakarta: Pustaka Baru Press.

Hidayat, Dede Rahmat. 2009. Ilmu Perilaku Manusia, Pengantar Psikologi untuk Tenaga Kesehatan Medis. Jakarta: Trans Info Media.

House, Sheryl K., Mary Ann Goetz, dan Susan Dowell. 2015. "Utilization of Nursing Home Residents for Development of Assessment Skills." Teaching and Learning in Nursing 10 (3): 128-31. https://doi.org/10.1016/j.teln.2015.01.005.

Insuranceinstitute. $2017 . \quad$ "Mentoring Models." $\quad$ Insuranceinstitute. 2017. https://www.insuranceinstitute.ca/fr/Mentoring/for-organizations/mentoring-models.

Janka, A., C. Adler, B. Brunner, S. Oppenrieder, dan S. Duschek. 2017. "Biofeedback Training in Crisis Managers: A Randomized Controlled Trial." Applied Psychophysiology Biofeedback 42 (2): 117-25. https://doi.org/10.1007/s10484-017-9360-6.

Kemdikbud. 2016. Pedoman Umum Ejaan Bahasa Indonesi. Pedoman Umum Ejaan Bahasa Indonesi. 4 ed. Vol. 4. Jakarta: Kementrian Pendidikan dan Kebudayaan RI. https://doi.org/10.5851/kosfa.2016.36.6.807.

Lestari, Citra Ega, dan Rosyidah. 2011. "Aanalisis Kepatuhan Perawat Pada Standar Asuhan Keperawatan Di Unit Rawat Inap Kelas III RSU PKU Muhammadiyah Bantul Yogyakarta Tahun 2010.” Jurnal Kesehatan Masyarakat (Journal of Public Health) Universitas Ahmad Dahlan 5 (1): 45-49.

Martini. 2007. "Hubungan Karakteristik Perawat, Sikap, Beban Kerja, Ketersediaan Fasilitas dengan Pendokumentasian Asuhan Keperawatan di Rawat Inap BPRSUD Kota Salatiga." Universitas Diponegoro Semarang.

Potter, dan Perry. 2010. Fundamental Keperawatan. 7 ed. Jakarta: Salemba Medika.

Saputra, Muhamad Andika Sasmita. 2017. Dengarkanlah. Yogyakarta: Deepublish. https://penerbitbukudeepublish.com/shop/buku-dengarkanlah/.

Utami, Ian. 2017. “Ketidak Patuhan.” $18 \quad$ Januari 2017.2017. https://www.scribd.com/document/336893143/ketidakpatuhan.

\section{HARVARD STYLE}

\section{CONTOH SITASI}

Ini adalah contoh kalimat yang dilengkapi dengan sitasi, beberapa pendapat yang diparaprase menjadi satu kalimat sehingga sitasinya digabung (Hidayat, 2009; House, Goetz dan Dowell, 2015; Bakri, 2017). Ini adalah contoh kalimat yang dilengkapi dengan sitasi, beberapa pendapat yang diparaprase menjadi satu kalimat sehingga sitasinya digabung (Martini, 2007; Potter dan Perry, 2010; Lestari dan Rosyidah, 2011; Kemdikbud, 2016). Ini adalah contoh kalimat yang dilengkapi dengan sitasi, menurut Janka et al., (2017) ini adalah contoh kalimat yang dilengkapi dengan sitasi. Utami (2017) ini adalah contoh kalimat yang dilengkapi dengan sitasi. Insuranceinstitute (2017) dan Saputra (2017) ini adalah contoh kalimat yang dilengkapi dengan sitasi. 


\section{CONTOH DAFTAR PUSTAKA}

Bakri, M. H. (2017) Manajemen Keperawatan, Konsep dan Aplikasi dalam Praktik Keperawatan Profesional. Yogyakarta: Pustaka Baru Press.

Hidayat, D. R. (2009) Ilmu Perilaku Manusia, Pengantar Psikologi untuk Tenaga Kesehatan Medis. Jakarta: Trans Info Media.

House, S. K., Goetz, M. A. dan Dowell, S. (2015) "Utilization of Nursing Home Residents for Development of Assessment Skills," Teaching and Learning in Nursing. Organization for Associate Degree Nursing., 10(3), hal. 128-131. doi: 10.1016/j.teln.2015.01.005.

Insuranceinstitute (2017) Mentoring Models, Insuranceinstitute. Tersedia pada: https://www.insuranceinstitute.ca/fr/Mentoring/for-organizations/mentoring-models $\quad$ (Diakses: 22 Desember 2017).

Janka, A. et al. (2017) "Biofeedback Training in Crisis Managers: A Randomized Controlled Trial," Applied Psychophysiology Biofeedback. Springer US, 42(2), hal. 117-125. doi: 10.1007/s10484-017-9360-6.

Kemdikbud (2016) Pedoman Umum Ejaan Bahasa Indonesi. 4 ed, Pedoman Umum Ejaan Bahasa Indonesi. 4 ed. Jakarta: Kementrian Pendidikan dan Kebudayaan RI. doi: 10.5851/kosfa.2016.36.6.807.

Lestari, C. E. dan Rosyidah (2011) “Aanalisis Kepatuhan Perawat Pada Standar Asuhan Keperawatan Di Unit Rawat Inap Kelas III RSU PKU Muhammadiyah Bantul Yogyakarta Tahun 2010," Jurnal Kesehatan Masyarakat (Journal of Public Health) Universitas Ahmad Dahlan, 5(1), hal. 45-49.

Martini (2007) Hubungan Karakteristik Perawat, Sikap, Beban Kerja, Ketersediaan Fasilitas dengan Pendokumentasian Asuhan Keperawatan di Rawat Inap BPRSUD Kota Salatiga. Universitas Diponegoro Semarang.

Potter dan Perry (2010) Fundamental Keperawatan. 7 ed. Jakarta: Salemba Medika.

Saputra, M. A. S. (2017) Dengarkanlah. Yogyakarta: Deepublish. Tersedia pada: https://penerbitbukudeepublish.com/shop/buku-dengarkanlah/.

Utami, I. (2017) Ketidak Patuhan, 18 Januari 2017. Tersedia pada: https://www.scribd.com/document/336893143/ketidakpatuhan (Diakses: 26 Juni 2017).

\section{IEEE STYLE}

\section{CONTOH SITASI}

Ini adalah contoh kalimat yang dilengkapi dengan sitasi, beberapa pendapat yang diparaprase menjadi satu kalimat sehingga sitasinya digabung [1]-[3]. Ini adalah contoh kalimat yang dilengkapi dengan sitasi, beberapa pendapat yang diparaprase menjadi satu kalimat sehingga sitasinya digabung [4]-[7]. Ini adalah contoh kalimat yang dilengkapi dengan sitasi [8]. Menurut Utami [9] ini adalah contoh kalimat yang dilengkapi dengan sitasi. Ini adalah contoh kalimat yang dilengkapi dengan sitasi, Insuranceinstitute [10] dan Saputra [11] ini adalah contoh kalimat yang dilengkapi dengan sitasi.

\section{CONTOH DAFTAR PUSTAKA}

[1] M. H. Bakri, Manajemen Keperawatan, Konsep dan Aplikasi dalam Praktik Keperawatan Profesional. Yogyakarta: Pustaka Baru Press, 2017.

[2] D. R. Hidayat, Ilmu Perilaku Manusia, Pengantar Psikologi untuk Tenaga Kesehatan Medis. Jakarta: Trans Info Media, 2009.

[3] S. K. House, M. A. Goetz, dan S. Dowell, "Utilization of Nursing Home Residents for Development of Assessment Skills," Teach. Learn. Nurs., vol. 10, no. 3, hal. 128-131, 2015, doi: 10.1016/j.teln.2015.01.005.

[4] Kemdikbud, Pedoman Umum Ejaan Bahasa Indonesi, 4 ed., vol. 4. Jakarta: Kementrian Pendidikan dan Kebudayaan RI, 2016.

[5] C. E. Lestari dan Rosyidah, "Aanalisis Kepatuhan Perawat Pada Standar Asuhan Keperawatan Di Unit Rawat Inap Kelas III RSU PKU Muhammadiyah Bantul Yogyakarta Tahun 2010,” J. Kesehat. Masy. (Journal Public Heal. Univ. Ahmad Dahlan, vol. 5, no. 1, hal. 45-49, 2011. 
[6] Martini, "Hubungan Karakteristik Perawat, Sikap, Beban Kerja, Ketersediaan Fasilitas dengan Pendokumentasian Asuhan Keperawatan di Rawat Inap BPRSUD Kota Salatiga," Universitas Diponegoro Semarang, 2007.

[7] Potter dan Perry, Fundamental Keperawatan, 7 ed. Jakarta: Salemba Medika, 2010.

[8] A. Janka, C. Adler, B. Brunner, S. Oppenrieder, dan S. Duschek, "Biofeedback Training in Crisis Managers: A Randomized Controlled Trial," Appl. Psychophysiol. Biofeedback, vol. 42, no. 2, hal. 117125, 2017, doi: 10.1007/s10484-017-9360-6.

[9] I. Utami, "Ketidak Patuhan," $18 \quad$ Januari 2017. https://www.scribd.com/document/336893143/ketidakpatuhan (diakses Jun 26, 2017).

[10] Insuranceinstitute, "Mentoring Models," $\quad$ Insuranceinstitute, 2017. https://www.insuranceinstitute.ca/fr/Mentoring/for-organizations/mentoring-models (diakses Des 22, 2017).

[11] M. A. S. Saputra, Dengarkanlah. Yogyakarta: Deepublish, 2017.

\section{VANCOUVER STYLE}

\section{CONTOH SITASI}

Ini adalah contoh kalimat yang dilengkapi dengan sitasi, beberapa pendapat yang diparaprase menjadi satu kalimat sehingga sitasinya digabung (1-3). Ini adalah contoh kalimat yang dilengkapi dengan sitasi, beberapa pendapat yang diparaprase menjadi satu kalimat sehingga sitasinya digabung (4-7). Ini adalah contoh kalimat yang dilengkapi dengan sitasi (8). Menurut Utami (9) ini adalah contoh kalimat yang dilengkapi dengan sitasi. Ini adalah contoh kalimat yang dilengkapi dengan sitasi, Insuranceinstitute (10) dan Saputra (11) ini adalah contoh kalimat yang dilengkapi dengan sitasi.

\section{CONTOH DAFTAR PUSTAKA}

1. Bakri MH. Manajemen Keperawatan, Konsep dan Aplikasi dalam Praktik Keperawatan Profesional. Yogyakarta: Pustaka Baru Press; 2017. 167 hal

2. Hidayat DR. Ilmu Perilaku Manusia, Pengantar Psikologi untuk Tenaga Kesehatan Medis. Jakarta: Trans Info Media; 2009. 1-187 hal.

3. House SK, Goetz MA, Dowell S. Utilization of Nursing Home Residents for Development of Assessment Skills. Teach Learn Nurs [Internet]. 2015;10(3):128-31. Tersedia pada: http://dx.doi.org/10.1016/j.teln.2015.01.005

4. Kemdikbud. Pedoman Umum Ejaan Bahasa Indonesi [Internet]. 4 ed. Vol. 4, Pedoman Umum Ejaan Bahasa Indonesi. Jakarta: Kementrian Pendidikan dan Kebudayaan RI; 2016. 195-422 hal. Tersedia pada: http://badanbahasa.kemdikbud.go.id/lamanbahasa/sites/default/files/PUEBI.pdf\#page=8\&zoom=auto,-195,422

5. Lestari CE, Rosyidah. Aanalisis Kepatuhan Perawat Pada Standar Asuhan Keperawatan Di Unit Rawat Inap Kelas III RSU PKU Muhammadiyah Bantul Yogyakarta Tahun 2010. J Kesehat Masy (Journal Public Heal Univ Ahmad Dahlan. 2011;5(1):45-9.

6. Martini. Hubungan Karakteristik Perawat, Sikap, Beban Kerja, Ketersediaan Fasilitas dengan Pendokumentasian Asuhan Keperawatan di Rawat Inap BPRSUD Kota Salatiga. Universitas Diponegoro Semarang; 2007.

7. Potter, Perry. Fundamental Keperawatan. 7 ed. Jakarta: Salemba Medika; 2010. 663 hal.

8. Janka A, Adler C, Brunner B, Oppenrieder S, Duschek S. Biofeedback Training in Crisis Managers: A Randomized Controlled Trial. Appl Psychophysiol Biofeedback. 2017;42(2):117-25.

9. Utami I. Ketidak Patuhan [Internet]. 18 Januari 2017. 2017 [dikutip 26 Juni 2017]. hal. 1-4. Tersedia pada: https://www.scribd.com/document/336893143/ketidakpatuhan

10. Insuranceinstitute. Mentoring Models [Internet]. Insuranceinstitute. 2017 [dikutip 22 Desember 2017]. Tersedia pada: https://www.insuranceinstitute.ca/fr/Mentoring/for-organizations/mentoring-models 
11. Saputra MAS. Dengarkanlah [Internet]. Yogyakarta: Deepublish; 2017. i-viii, 1-161. Tersedia pada: https://penerbitbukudeepublish.com/shop/buku-dengarkanlah/

\section{NATURE STYLE}

\section{CONTOH SITASI}

Ini adalah contoh kalimat yang dilengkapi dengan sitasi, beberapa pendapat yang diparaprase menjadi satu kalimat sehingga sitasinya digabung ${ }^{-3}$. Ini adalah contoh kalimat yang dilengkapi dengan sitasi, beberapa pendapat yang diparaprase menjadi satu kalimat sehingga sitasinya digabung ${ }^{4-7}$. Ini adalah contoh kalimat yang dilengkapi dengan sitasi ${ }^{8}$, tulisan tulisan tulisan. Menurut Utami ${ }^{9}$ ini adalah contoh kalimat yang dilengkapi dengan sitasi. Ini adalah contoh kalimat yang dilengkapi dengan sitasi, Insuranceinstitute ${ }^{10}$ dan Saputra ${ }^{11}$ ini adalah contoh kalimat yang dilengkapi dengan sitasi.

\section{CONTOH DAFTAR PUSTAKA}

1. Bakri, M. H. Manajemen Keperawatan, Konsep dan Aplikasi dalam Praktik Keperawatan Profesional. (Pustaka Baru Press, 2017).

2. Hidayat, D. R. Ilmu Perilaku Manusia, Pengantar Psikologi untuk Tenaga Kesehatan Medis. (Trans Info Media, 2009).

3. House, S. K., Goetz, M. A. \& Dowell, S. Utilization of Nursing Home Residents for Development of Assessment Skills. Teach. Learn. Nurs. 10, 128-131 (2015).

4. Kemdikbud. Pedoman Umum Ejaan Bahasa Indonesi. Pedoman Umum Ejaan Bahasa Indonesi vol. 4 (Kementrian Pendidikan dan Kebudayaan RI, 2016).

5. Lestari, C. E. \& Rosyidah. Aanalisis Kepatuhan Perawat Pada Standar Asuhan Keperawatan Di Unit Rawat Inap Kelas III RSU PKU Muhammadiyah Bantul Yogyakarta Tahun 2010. J. Kesehat. Masy. (Journal Public Heal. Univ. Ahmad Dahlan 5, 45-49 (2011).

6. Martini. Hubungan Karakteristik Perawat, Sikap, Beban Kerja, Ketersediaan Fasilitas dengan Pendokumentasian Asuhan Keperawatan di Rawat Inap BPRSUD Kota Salatiga. (Universitas Diponegoro Semarang, 2007).

7. Potter \& Perry. Fundamental Keperawatan. (Salemba Medika, 2010).

8. Janka, A., Adler, C., Brunner, B., Oppenrieder, S. \& Duschek, S. Biofeedback Training in Crisis Managers: A Randomized Controlled Trial. Appl. Psychophysiol. Biofeedback 42, 117-125 (2017).

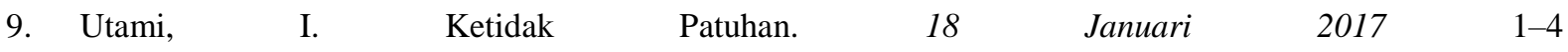
https://www.scribd.com/document/336893143/ketidakpatuhan (2017).

10. Insuranceinstitute. Mentoring Models. https://www.insuranceinstitute.ca/fr/Mentoring/for-organizations/mentoring-models (2017).

11. Saputra, M. A. S. Dengarkanlah. (Deepublish, 2017). 


\section{MODERN HUMANITIS RESEARCH ASSOCIATION (MHRA) STYLE}

\section{CONTOH SITASI}

Untuk penggabungan sitasi sama dengan contoh nature style. Ini adalah contoh kalimat yang dilengkapi dengan sitasi ${ }^{1}$, Ini adalah contoh kalimat yang dilengkapi dengan sitasi ${ }^{2}$. Ini adalah contoh kalimat yang dilengkapi dengan sitasi. Ini adalah contoh kalimat yang dilengkapi dengan sitasi, Saputra $(2017)^{3}$ ini adalah contoh kalimat yang dilengkapi dengan sitasi.

\section{CONTOH DAFTAR PUSTAKA}

Kemdikbud, Pedoman Umum Ejaan Bahasa Indonesi, Pedoman Umum Ejaan Bahasa Indonesi, 4 ed. (Jakarta: Kementrian Pendidikan dan Kebudayaan RI, 2016), IV <https://doi.org/10.5851/kosfa.2016.36.6.807>

Lestari, Citra Ega, dan Rosyidah, "Aanalisis Kepatuhan Perawat Pada Standar Asuhan Keperawatan Di Unit Rawat Inap Kelas III RSU PKU Muhammadiyah Bantul Yogyakarta Tahun 2010," Jurnal Kesehatan Masyarakat (Journal of Public Health) Universitas Ahmad Dahlan, 5.1 (2011), 45-49

Martini, "Hubungan Karakteristik Perawat, Sikap, Beban Kerja, Ketersediaan Fasilitas dengan Pendokumentasian Asuhan Keperawatan di Rawat Inap BPRSUD Kota Salatiga” (Universitas Diponegoro Semarang, 2007)

Potter, dan Perry, Fundamental Keperawatan, 7 ed. (Jakarta: Salemba Medika, 2010)

Saputra, Muhamad Andika Sasmita, Dengarkanlah (Yogyakarta: Deepublish, 2017) <https://penerbitbukudeepublish.com/shop/buku-dengarkanlah/>

Utami, Ian, “Ketidak Patuhan," 18 Januari 2017, 2017, hal. 1-4 <https://www.scribd.com/document/336893143/ketidakpatuhan> [diakses 26 Juni 2017]

\section{Foot Note Referensi Modern Humanitis Research Association (Mhra) Style}

\footnotetext{
${ }^{1}$ Kemdikbud, Pedoman Umum Ejaan Bahasa Indonesi, Pedoman Umum Ejaan Bahasa Indonesi, 4 ed. (Jakarta: Kementrian Pendidikan dan Kebudayaan RI, 2016), IV <https://doi.org/10.5851/kosfa.2016.36.6.807>; Citra Ega Lestari dan Rosyidah, "Aanalisis Kepatuhan Perawat Pada Standar Asuhan Keperawatan Di Unit Rawat Inap Kelas III RSU PKU Muhammadiyah Bantul Yogyakarta Tahun 2010," Jurnal Kesehatan Masyarakat (Journal of Public Health) Universitas Ahmad Dahlan, 5.1 (2011), 45-49; Martini, "Hubungan Karakteristik Perawat, Sikap, Beban Kerja, Ketersediaan Fasilitas dengan Pendokumentasian Asuhan Keperawatan di Rawat Inap BPRSUD Kota Salatiga" (Universitas Diponegoro Semarang, 2007); Potter dan Perry, Fundamental Keperawatan, 7 ed. (Jakarta: Salemba Medika, 2010).

2 Ian Utami, "Ketidak Patuhan," 18 Januari 2017, 2017, hal. 1-4

<https://www.scribd.com/document/336893143/ketidakpatuhan> [diakses 26 Juni 2017].

${ }^{3}$ Muhamad Andika Sasmita Saputra, Dengarkanlah (Yogyakarta: Deepublish, 2017)

<https://penerbitbukudeepublish.com/shop/buku-dengarkanlah/>.
} 


\section{HAL-HAL YANG HARUS DIPERHATIKAN:}

1. Mengutip dari sumber ke dua/ketiga, hal ini sebaiknya ditinggalkan.

Contoh :

a. (Saputra dalam Sophia, 2020) : ini artinya ungkapan dari Saputra dikutip oleh Shopia

b. (Saputra dalam Sophia dalam Halimah, 2020) : ini artinya ungkapan dari Saputra dikutip oleh Shopia dan diambil lagi oleh Halimah dan dijadikan referensi oleh Anda. Jelas ini "SALAH".

Maka sitasi dan referensi yang tepat adalah mencari referensi utamanya dan cantumkan sebagai sumber utama, seperti ini (Saputra, 2017). "Referensi yang baik adalah referensi yang diambil dari sumber utama".

Beberapa institusi menentukan referensi yang wajib digunakan, misalnya lima tahun terakhir untuk jurnal dan sepuluh tahun terakhir untuk buku, untuk jurnal maka akan lebih baik bila mencari jurnal yang topiknya sama namun tahunnya terupdate, begitu juga dengan buku yang telah lebih dari batas waktu yang ditentukan, namun apabila benar-benar tidak menemukan keterbaruan tahun dari kalimat yang dikutip, maka akan lebih baik jika dikonsultasikan pada pihak institusi apakah dimaklumi atau tidak.

2. Mengutip suatu pendapat/ungkapan namun lupa atau sengaja tidak mencantumkan sitasi dan referensi yang dikutip, hal ini akan berdampak pada deteksi plagiarisme terhadap ungkapan yang dibuat.

3. Tidak mengikuti aturan sitasi dan referensi yang ditentukan dan tidak konsisten dengan style yang dipakai.

4. Gabungkan rangkaian referensi ke halaman yang berbeda, hal ini bertujuan agar tidak terjadi miss referensi ketika dibaca.

Contoh yang KURANG BAIK:

House, Sheryl K., Mary Ann Goetz, dan Susan Dowell. 2015. "Utilization of Nursing Home Residents

for Development of Assessment Skills." Teaching and Learning in Nursing 10 (3): 128-31. https://doi.org/10.1016/j.teln.2015.01.005.

Contoh yang BAIK: Enter awal referensi ke halaman baru

House, Sheryl K., Mary Ann Goetz, dan Susan Dowell. 2015. "Utilization of Nursing Home Residents for Development of Assessment Skills." Teaching and Learning in Nursing 10(3): 128-31. http://dx.doi.org/10.1016/j.teln.2015.01.005.

5. Menghargai karya/pemikiran orang lain dengan mencantumkannya sebagai sumber referensi, sama halnya dengan menghargai karya sendiri dan ingin dihargai oleh orang lain. 